Jurnal Ilmiah Matematika dan Pendidikan Matematika (JMP)

Vol. 11 No. 2, Desember 2019, hal. 11-18

ISSN (Cetak) : 2085-1456; ISSN (Online) : 2550-0422

\title{
TEOREMA TITIK TETAP UNTUK PEMETAAN KANNAN PADA RUANG METRIK MODULAR TERITLAK
}

\author{
Lusi Harini \\ Universitas Negeri Yogyakarta \\ Email : lusi.harini@uny.ac.id
}

\begin{abstract}
In this paper, we will discuss about fixed point theorems in generalized modular metric space for Kannan- $D_{\lambda}$ type mapping. The existence of the fixed point of this mapping is guaranteed by providing that the mapping domain is a $D_{\lambda}$-finite set and the Kannan- $D_{\lambda}$ mapping constant $\alpha \in\left(0, \frac{1}{2}\right)$ satisfied $\alpha K<1$ where $K$ is a constant from the axiom of generalized modular metric space.
\end{abstract}

Keywords: generalized modular metric space, fixed point, Kannan mapping.

\begin{abstract}
ABSTRAK. Dalam tulisan ini, akan dibahas mengenai teorema titik tetap pada ruang metrik modular teritlak (generalized modular metric space) untuk pemetaan Kannan- $D_{\lambda}$. Eksistensi titik tetap pemetaan Kannan- $D_{\lambda}$ dijamin dengan memberikan syarat domain pemetaan tersebut merupakan himpunan yang terbatas- $D_{\lambda}$ dan konstanta pemetaan Kannan- $D_{\lambda}$ yaitu $\alpha \in\left(0, \frac{1}{2}\right)$ memenuhi $\alpha K<1$ dengan $\mathrm{K}$ merupakan konstanta yang memenuhi aksioma dari metrik modular teritlak.
\end{abstract}

Kata Kunci: ruang metrik modular teritlak, titik tetap, pemetaan Kannan.

\section{PENDAHULUAN}

Teorema titik tetap merupakan salah satu hasil dari penelitian matematika analisis yang cukup luas aplikasinya. Kegunaan teorema ini diantaranya adalah untuk membuktikan eksistensi solusi dari suatu sistem persamaan diferensial, menentukan solusi pendekatan dari suatu fungsi, dan masalah lain yang berkonsep mengenai kestabilan. Titik tetap adalah salah satu bidang yang banyak diteliti dan telah dikembangkan yang bermula dari munculnya Prinsip Kontraksi Banach di tahun 1922.

Jenis pemetaan yang berbeda dari pemetaan kontraksi didefinisikan oleh Kannan (1969) yang selanjutnya disebut dengan pemetaan Kannan. Teorema titik tetap untuk pemetaan Kannan telah dibuktikan dalam beberapa tulisan, salah satu diantaranya adalah Ghoncheh (2015) yang mengembangkan ke ruang bermodular. 
Jenis struktur ruang baru diperkenalkan oleh Jleli dan Samet (2015) yang disebut ruang metrik teritlak (generalized metric space). Ruang tersebut mewadahi ruang bermodular yang memiliki sifat Fatou. Selanjutnya, Turkoglu dan Manav (2018) membentuk ruang yang disebut ruang metrik modular teritlak (generalized modular metric space) dengan adaptasi dari ruang metrik modular Chistyakov (2010). Telah dibuktikan teorema titik tetap untuk pemetaan kontraksi dan pemetaan kuasi-kontraksi dalam Turkoglu dan Manav (2018). Dalam paper ini, akan diselidiki syarat yang dibutuhkan untuk menjamin eksistensi titik tetap pemetaan Kannan dalam ruang metrik modular teritlak. Penelitian ini bertujuan untuk menambah hasil penemuan dalam bidang matematika analisis yang diharapkan dapat memperluas aplikasi dari pemetaan Kannan karena berada di ruang yang lebih luas.

\section{HASIL DAN PEMBAHASAN}

Definisi dari ruang metrik modular teritlak menurut Turkoglu dan Manav (2018) adalah sebagai berikut.

Definisi 2.1. Diberikan $X$ sebarang himpunan tak kosong. Fungsi D: $(0, \infty) \times X \times$ $X \rightarrow[0, \infty]$ disebut metrik modular teritlak pada $X$ apabila memenuhi tiga aksioma berikut:

(1) Jika $D_{\lambda}(x, y)=0$ untuk suatu $\lambda$ maka $x=y$ untuk semua $x, y \in X$.

(2) Untuk semua $x, y \in X$ berlaku $D_{\lambda}(x, y)=D_{\lambda}(y, x)$ untuk semua $\lambda>0$.

(3) Terdapat $\mathrm{K}>0$ sehingga untuk $x, y \in X$ dan $\left\{x_{n}\right\} \subseteq X$ dengan $\lim _{\mathrm{n} \rightarrow \infty} D_{\lambda}\left(x_{n}, x\right)=0 \quad$ untuk suatu $\quad \lambda>0, \quad$ maka $\mathrm{D}_{\lambda}(\mathrm{x}, \mathrm{y}) \leq \mathrm{K} \limsup _{\mathrm{n} \rightarrow \infty} D_{\lambda}\left(x_{n}, y\right)$.

Selanjutnya, himpunan tak kosong $\mathrm{X}$ yang dilengkapi dengan metrik modular teritlak, dinotasikan dengan $(X, D)$ yang disebut ruang metrik modular teritlak. 
Beberapa contoh mengenai ruang metrik modular teritlak dapat dilihat secara lengkap dalam Turkoglu dan Manav (2018). Berikut diberikan contoh sederhana untuk memudahkan gambaran mengenai ruang metrik modular teritlak.

Contoh 2.2. Diberikan sebarang himpunan tak kosong $X$. Didefinisikan fungsi $D^{0}:(0, \infty) \times X \times X \rightarrow[0, \infty]$ dengan $D_{\lambda}^{0}(x, y)=0$ jika $x=y$, dan $D_{\lambda}^{0}(x, y)=$ $\infty$ jika $x \neq y$, untuk semua $\lambda>0$. Dapat ditunjukkan bahwa fungsi $D^{0}$ memenuhi ketiga aksioma metrik modular teritlak pada Definisi 2.1. Lebih lanjut, jika $d$ metrik pada $X$ dan $\psi$ sebarang fungsi positif maka fungsi $D^{1}$ dengan definisi $D_{\lambda}^{1}(x, y)=\frac{d(x, y)}{\psi(\lambda)}$ merupakan metrik modular teritlak pada $X$.

Diberikan $(X, D)$ ruang metrik modular teritlak dan $x_{0} \in X$. Dibentuk himpunan $X_{D}=\left\{x \in X: D_{\lambda}\left(x, x_{0}\right) \rightarrow 0\right.$ untuk $\left.\lambda \rightarrow \infty\right\}$. Untuk pembahasan lebih lanjut, ruang metrik modular teritlak yang dimaksud adalah himpunan $X_{D}$ tersebut.

Selanjutnya, akan diberikan definisi mengenai kekonvergenan barisan, himpunan tertutup, dan himpunan terbatas dalam ruang metrik modular teritlak yang diperlukan dalam pembahasan lebih lanjut.

Definisi 2.3. Diberikan $X_{D}$ ruang metrik modular teritlak dan $\lambda>0$.

(1) Barisan $\left\{x_{n}\right\} \subseteq X_{D}$ dikatakan barisan konvergen- $D_{\lambda}$ ke $x \in X_{D}$ jika dan hanya jika $D_{\lambda}\left(x_{n}, x\right) \rightarrow 0$ untuk $n \rightarrow \infty$. Lebih lanjut, $x$ disebut limit- $D_{\lambda}$ barisan $\left\{x_{n}\right\}$.

(2) Barisan $\left\{x_{n}\right\} \subseteq X_{D}$ dikatakan barisan Cauchy- $D_{\lambda}$ jika dan hanya jika $D_{\lambda}\left(x_{n}, x_{m}\right) \rightarrow 0$ untuk $n, m \rightarrow \infty$.

(3) Himpunan $C \subseteq X_{D}$ dikatakan tertutup- $D_{\lambda}$ apabila untuk setiap barisan $\left\{x_{n}\right\} \subseteq C$ yang konvergen- $D_{\lambda}$ ke $x \in X_{D}$ berakibat $x \in C$.

(4) Himpunan $C \subseteq X_{D}$ dikatakan lengkap- $D_{\lambda}$ apabila untuk setiap barisan Cauchy- $D_{\lambda}$ di $C$ merupakan barisan konvergen- $D_{\lambda}$ di $C$.

(5) Himpunan $C \subseteq X_{D}$ dikatakan terbatas- $D_{\lambda}$ apabila 


$$
\delta_{D_{\lambda}}(C)=\sup \left\{D_{\lambda}(x, y): x, y \in C\right\}<\infty .
$$

Diperhatikan bahwa jika barisan $\left\{x_{n}\right\} \subseteq X_{D}$ konvergen- $D_{\lambda}$ maka limit- $D_{\lambda}$ barisan $\left\{x_{n}\right\}$ tunggal. Andaikan barisan $\left\{x_{n}\right\}$ konvergen- $D_{\lambda}$ ke $x, y \in X_{D}$, dengan kata lain $D_{\lambda}\left(x_{n}, x\right) \rightarrow 0$ dan $D_{\lambda}\left(x_{n}, y\right) \rightarrow 0$ untuk $n \rightarrow \infty$. Berdasarkan aksioma ketiga metrik modular teritlak diperoleh $D_{\lambda}(x, y) \leq K \limsup _{n \rightarrow \infty} D_{\lambda}\left(x_{n}, y\right)=0$. Akibatnya, $x=y$.

Lebih lanjut, jika $X_{D}$ ruang metrik modular yang lengkap- $D_{\lambda}$ dan $C \subseteq X_{D}$ himpunan tertutup- $D_{\lambda}$ maka $C$ merupakan himpunan lengkap- $D_{\lambda}$. Selain itu, barisan yang konvergen- $D_{\lambda}$ tidak ada jaminan barisan tersebut merupakan barisan Cauchy- $D_{\lambda}$ dan barisan konvergen- $D_{\lambda}$ untuk suatu $\lambda>0$ tidak menjamin barisan tersebut juga konvergen- $D_{\lambda}$ untuk $\lambda>0$ yang lain. Oleh karena itu, diberikan definisi dari kondisi- $\Delta_{2}$ seperti pada ruang metrik modular.

Definisi 2.4. Ruang metrik modular teritlak $X_{D}$ dikatakan memenuhi kondisi- $\Delta_{2}$ apabila untuk setiap barisan $\left\{x_{n}\right\} \subseteq X_{D}$ konvergen- $D_{\lambda}$ untuk suatu $\lambda>0$ berakibat $\left\{x_{n}\right\} \subseteq X_{D}$ konvergen- $D_{\lambda}$ untuk setiap $\lambda>0$.

Sebelum ke pembahasan utama dalam tulisan ini, diberikan definisi dari pemetaan Kannan di ruang metrik modular teritlak.

Definisi 2.5. Diberikan $X_{D}$ ruang metrik modular yang diperumum, $\lambda>0$, dan $C \subseteq X_{D}$. Pemetaan $T: C \rightarrow C$ disebut pemetaan Kannan- $D_{\lambda}$ apabila terdapat $\alpha \in\left(0, \frac{1}{2}\right)$ sehingga untuk setiap $x, y \in C$ berlaku

$$
D_{\lambda}(T(x), T(y)) \leq \alpha\left(D_{\lambda}(T(x), x)+D_{\lambda}(T(y), y)\right) .
$$

Lebih lanjut, bilangan $\alpha$ tersebut dinamakan konstanta Kannan- $D_{\lambda}$.

Selanjutnya perlu diingat kembali, apabila $T: X \rightarrow X$ suatu pemetaan, maka $x \in X$ disebut titik tetap pemetaan $T$ jika $T(x)=x$. Apabila pemetaan Kannan- $D_{\lambda}$ memiliki titik tetap, pembuktian ketunggalan titik tetapnya diperlukan lemma berikut. 
Lemma 2.6. Diberikan $X_{D}$ ruang metrik modular teritlak, $\lambda>0, C \subseteq X_{D}$ tak kosong dan terbatas- $D_{\lambda}$, dan $T: C \rightarrow C$ pemetaan Kannan- $D_{\lambda}$ dengan konstanta Kannan- $D_{\lambda} \alpha$. Jika $u \in C$ titik tetap $T$ maka $D_{\lambda}(u, u)=0$.

Bukti. Diketahui $u \in C$ titik tetap $T$, berarti $T(u)=u$. Diperhatikan bahwa,

$$
\begin{aligned}
D_{\lambda}(u, u)=D_{\lambda}(T(u), T(u)) \leq & \alpha\left(D_{\lambda}(T(u), u)+D_{\lambda}(T(u), u)\right) \\
& =\alpha\left(\left(D_{\lambda}(u, u)+D_{\lambda}(u, u)\right)\right. \\
& =2 \alpha D_{\lambda}(u, u) .
\end{aligned}
$$

Karena $C$ terbatas $-D_{\lambda}, 2 \alpha<1$, dan $D_{\lambda}(u, u) \leq 2 \alpha D_{\lambda}(u, u)$ maka diperoleh $D_{\lambda}(u, u)=0$.

Teorema 2.7. Diberikan $X_{D}$ ruang metrik modular teritlak, $\lambda>0, C \subseteq X_{D}$ tak kosong dan terbatas- $D_{\lambda}$, dan $T: C \rightarrow C$ pemetaan Kannan- $D_{\lambda}$ dengan konstanta Kannan- $D_{\lambda} \alpha$. Jika $T$ memiliki titik tetap, maka titik tetap $T$ tunggal.

Bukti. Andaikan $x, y \in C$ merupakan titik tetap pemetaan $T$. Dengan demikian $T(x)=x$ dan $T(y)=y$. Karena $T$ pemetaan Kannan- $D_{\lambda}$ dengan suatu konstanta Kannan- $D_{\lambda} \alpha \in\left(0, \frac{1}{2}\right)$ maka

$$
\begin{aligned}
D_{\lambda}(x, y)=D_{\lambda}(T(x), T(y)) \leq & \alpha\left(D_{\lambda}(T(x), x)+D_{\lambda}(T(y), y)\right) \\
& =\alpha\left(D_{\lambda}(x, x)+D_{\lambda}(y, y)\right) .
\end{aligned}
$$

Berdasarkan Lemma 2.6 diperoleh $D_{\lambda}(x, x)=D_{\lambda}(y, y)=0$. Akibatnya, didapatkan $D_{\lambda}(x, y)=0$ sehingga $x=y$.

Berikut diberikan teorema yang menjamin eksistensi dari titik tetap pemetaan Kannan- $D_{\lambda}$.

Teorema 2.8. Diberikan $\lambda>0$ dan $X_{D}$ ruang metrik modular teritlak lengkap- $D_{\lambda}$ dengan konstanta $K$ yang memenuhi Aksioma 3 pada Definisi 2.1 serta $C \subseteq X_{D}$ himpunan tak kosong tertutup- $D_{\lambda}$ dan terbatas $D_{\lambda}$. Apabila $T: C \rightarrow C$ merupakan pemetaan Kannan- $D_{\lambda}$ dengan konstanta Kannan- $D_{\lambda} \alpha \in\left(0, \frac{1}{2}\right)$ memenuhi $\alpha K<1$ maka $T$ memiliki titik tetap tunggal. 
Bukti. Diambil sebarang $x \in C$. Dibentuk barisan $\left\{x_{n}\right\} \in C$ dengan definisi sebagai berikut,

$x_{1}=T(x), \quad x_{2}=T\left(x_{1}\right)=T(T(x))=T^{2}(x), \quad x_{3}=T\left(x_{2}\right)=T\left(T^{2}(x)\right)=$ $T^{3}(x)$, dan seterusnya sehingga secara umum $x_{n}=T^{n}(x)$ untuk setiap $n \in \mathbb{N}$.

Berdasarkan definisi dari pemetaan Kannan- $D_{\lambda}$ maka diperoleh,

$$
\begin{aligned}
D_{\lambda}\left(x_{n}, x_{n+1}\right)= & D_{\lambda}\left(T\left(x_{n-1}\right), T\left(x_{n}\right)\right) \\
& \leq \alpha\left(D_{\lambda}\left(T\left(x_{n-1}\right), x_{n-1}\right)+D_{\lambda}\left(T\left(x_{n}\right), x_{n}\right)\right) \\
& =\alpha\left(D_{\lambda}\left(x_{n}, x_{n-1}\right)+D_{\lambda}\left(x_{n+1}, x_{n}\right)\right) \\
& =\alpha D_{\lambda}\left(x_{n}, x_{n-1}\right)+\alpha D_{\lambda}\left(x_{n+1}, x_{n}\right) .
\end{aligned}
$$

Akibatnya diperoleh

$$
\begin{aligned}
& (1-\alpha) D_{\lambda}\left(x_{n}, x_{n+1}\right) \leq \alpha D_{\lambda}\left(x_{n-1}, x_{n}\right) \\
& \Leftrightarrow \quad D_{\lambda}\left(x_{n}, x_{n+1}\right) \quad \leq \frac{\alpha}{1-\alpha} D_{\lambda}\left(x_{n-1}, x_{n}\right) .
\end{aligned}
$$

Dengan demikian, secara induktif dapat ditunjukkan bahwa

$$
D_{\lambda}\left(x_{n}, x_{n+1}\right) \leq\left(\frac{\alpha}{1-\alpha}\right)^{n} D_{\lambda}(x, T(x)) .
$$

Selanjutnya, ditinjau dua kasus berikut.

Kasus 1. Apabila terdapat $n \in \mathbb{N}$ sehingga $x_{n}=x$ maka diperoleh

$$
\begin{aligned}
& D_{\lambda}(x, T(x))=D_{\lambda}\left(x_{n}, T\left(x_{n}\right)\right) \\
& =D_{\lambda}\left(x_{n}, x_{n+1}\right) \\
& \leq\left(\frac{\alpha}{1-\alpha}\right)^{n} D_{\lambda}(x, T(x)) .
\end{aligned}
$$

Sebut $h=\frac{\alpha}{1-\alpha}$ maka $0<h<1$. Akibatnya diperoleh

$$
\left(1-h^{n}\right) D_{\lambda}(x, T(x)) \leq 0 .
$$

Dengan demikian, $D_{\lambda}(x, T(x))=0$ yang berarti $T(x)=x$ dan bukti selesai.

Kasus 2. Untuk setiap $n \in \mathbb{N}$ berlaku $x_{n} \neq x$. Diambil sebarang $p \in \mathbb{N}$ diperhatikan bahwa, untuk setiap $n \in \mathbb{N}$ berlaku

$$
\begin{aligned}
D_{\lambda}\left(T^{n}(x), T^{n+p}(x)\right) \leq & \alpha\left(D_{\lambda}\left(T^{n-1}(x), T^{n}(x)\right)+D_{\lambda}\left(T^{n+p-1}(x), T^{n+p}(x)\right)\right) \\
& \leq \alpha\left(h^{n-1} D_{\lambda}(x, T(x))+h^{n+p-1} D_{\lambda}(x, T(x))\right) .
\end{aligned}
$$


Akibatnya, dengan mengambil $n \rightarrow \infty$ diperoleh $D_{\lambda}\left(T^{n}(x), T^{n+p}(x)\right) \rightarrow 0$ karena $h<1$. Dengan demikian, diperoleh barisan $\left\{x_{n}\right\} \subseteq C$ merupakan barisan Cauchy- $D_{\lambda}$ di $X_{D}$. Karena $X_{D}$ lengkap- $D_{\lambda}$ dan $C$ tertutup- $D_{\lambda}$ maka terdapat $u \in C$ sehingga $\left\{x_{n}\right\}$ konvergen- $D_{\lambda}$ ke $u$.

Akan ditunjukkan $u$ merupakan titik tetap T. Berdasarkan Aksioma 3 pada Definisi 2.1 diperoleh bahwa,

$$
\begin{gathered}
D_{\lambda}(T(u), u) \leq K \limsup _{n \rightarrow \infty} D_{\lambda}\left(T(u), T^{n}(x)\right) \\
\leq \operatorname{Klimsup}_{n \rightarrow \infty} \alpha\left(D_{\lambda}(T(u), u)\right. \\
\left.+D_{\lambda}\left(T^{n}(x), T^{n-1}(x)\right)\right) \\
\Leftrightarrow(1-\alpha K) D_{\lambda}(T(u), u) \leq \alpha K \limsup _{n \rightarrow \infty} D_{\lambda}\left(T^{n}(x), T^{n-1}(x)\right) \\
\leq \alpha K \limsup _{n \rightarrow \infty} h^{n-1} D_{\lambda}(x, T(x))=0 .
\end{gathered}
$$

Karena $\alpha K<1$ maka $D_{\lambda}(T(u), u)=0$, akibatnya $T(u)=u$. Jadi terbukti bahwa $T$ memiliki titik tetap. Selanjutnya, ketunggalan dari titik tetap $T$ dijamin oleh Teorema 2.7.

Apabila pemetaan $T: C \rightarrow C$ memenuhi sifat untuk setiap barisan $\left\{x_{n}\right\} \subseteq C$ yang konvergen- $D_{\lambda}$ ke suatu $x \in X_{D}$ berakibat barisan $\left\{T\left(x_{n}\right)\right\}$ konvergen- $D_{\lambda}$ ke $T(x)$ maka $T$ disebut pemetaan kontinu- $D_{\lambda}$ secara barisan. Eksistensi titik tetap pemetaan Kannan- $D_{\lambda} T$ yang memenuhi sifat tersebut, dituangkan dalam teorema berikut.

Teorema 2.9. Diberikan $X_{D}$ ruang metrik modular teritlak, $\lambda>0, C \subseteq X_{D}$ tak kosong dan $T: C \rightarrow C$ pemetaan Kannan- $D_{\lambda}$ yang kontinu- $D_{\lambda}$ secara barisan. Jika terdapat $x \in C$ sehingga barisan $\left\{T^{n}(x)\right\}$ memiliki subbarisan $\left\{T^{n_{k}}(x)\right\}$ yang konvergen- $D_{\lambda}$ ke $x$ maka $x$ merupakan titik tetap $T$ dan tunggal.

Bukti. Diketahui barisan $\left\{T^{n}(x)\right\}$ memiliki subbarisan $\left\{T^{n_{k}}(x)\right\}$ yang konvergen$D_{\lambda}$ ke $x$. Karena $T$ kontinu- $D_{\lambda}$ secara barisan maka $\left\{T^{n_{k}}(x)\right\}$ konvergen- $D_{\lambda}$ ke $T(x)$. Dengan demikian diperoleh, 


$$
\lim _{k \rightarrow \infty} D_{\lambda}\left(T^{n_{k}}(x), T(x)\right)=0 .
$$

Hal ini berakibat $\limsup _{k \rightarrow \infty} D_{\lambda}\left(T^{n_{k}}(x), T(x)\right)=0$ sehingga berdasarkan Aksioma 3 pada Definisi 2.1 diperoleh,

$$
D_{\lambda}(x, T(x)) \leq K \limsup _{k \rightarrow \infty} D_{\lambda}\left(T^{n_{k}}(x), T(x)\right)=0 .
$$

Dengan demikian $T(x)=x$ yaitu $x$ merupakan titik tetap $T$. Untuk ketunggalan titik tetap $T$ dijamin oleh Teorema 2.7.

\section{KESIMPULAN DAN SARAN}

Dari pembahasan di atas dapat disimpulkan bahwa pemetaan Kannan- $D_{\lambda}$ di ruang metrik modular teritlak memiliki titik tetap tunggal dengan pemberian syarat domain pemetaan tersebut terbatas- $D_{\lambda}$ dan tertutup- $D_{\lambda}$, serta konstanta Kannan- $D_{\lambda} \quad \alpha$ memenuhi $\alpha K<1$ dengan $K$ konstanta pada definisi metrik modular teritlak. Mengingat masih banyaknya jenis pemetaan yang ada di ruang metrik, modular, dan metrik modular yang telah dibuktikan eksistensi titik tetapnya, maka tidak menutup kemungkinan pemetaan-pemetaan tersebut bisa dikembangkan dalam ruang metrik modular teritlak.

\section{DAFTAR PUSTAKA}

Ghoncheh, H.B.M., Some Fixed Point Theorems for Kannan Mapping in The Modular Spaces, Ciencia eNatura, 37 (2015), 462-466.

Jleli, M., Samet, B.M. A Generalized Metric Space and Related Fixed Point Theorems, Fixed Point Theory and Application, 61 (2015).

Kannan, R. Some Results on Fixed Points II. American Mathematical Monthly, 76 (1969), 405-408.

Turkoglu, D., Manav, N., Fixed Point Theorem in A New Type of Modular Metric Spaces, Fixed Point Theory and Application, 25 (2018).

Chistyakov, V. V, Modular Metric Spaces I, Nonlinear Analysis, Elsevier, 72 (20100. 